\title{
LA GUERRA POR OTROS MEDIOS, COMUNICACIÓN INSURGENTE Y PROCESO REVOLUCIONARIO EN EL SALVADOR (1970-1992). SAN SALVADOR: UCA EDITORES, 2017. 564 PP. ISBN: 9789996110375
}

Jorge Juárez Ávila Instituto de Estudios Históricos y Antropológicos Universidad de El Salvador jorge.juarez@ues.edu.sv

Recepción:

4 de diciembre de 2017

Aceptación:

11 de diciembre de 2017 



\title{
LA GUERRA POR OTROS MEDIOS, COMUNICACIÓN INSURGENTE Y PROCESO REVOLUCIONARIO EN EL SALVADOR (1970-1992). SAN SALVA- DOR: UCA EDITORES, 2017. 564 PP. ISBN: 9789996110375
}

\author{
Jorge Juárez Ávila \\ Instituto de Estudios Históricos y Antropológicos \\ Universidad de El Salvador \\ jorge.juarez@ues.edu.sv
}

Buenas tardes a todos, a todas. Quiero en primer lugar agradecer a Eudald por invitarme a compartir con ustedes algunas reflexiones sobre su libro que ahora UCA editores presenta. Por supuesto, también agradezco a UCA editores por este espacio.

Para comentar el libro de Eudald, permítanme ubicarme en la noción “operación historiográfica, planteada por Michel De Certeau.

$\mathrm{Y}$ es que por insignificante y extraño que parezca, el libro que hoy presenta Eudald y UCA Editores tiene ya una trayectoria en la cual ha sufrido un proceso de mutación hasta llegar aquí y probablemente, en el futuro, quizá más lento o quizá más rápido, sufrirá o gozará de otras transformaciones. En general, este texto histórico, enuncia una operación que se sitúa dentro de un conjunto de prácticas. Según Michel De Certeau, este aspecto es primordial, es lo esencial en una investigación científica. Es decir, De Certeau, plantea que la operación histórica implica la combinación de un lugar social, de prácticas científicas y de una escritura.

El estudio de la guerra civil salvadoreña ha sido abordado por diversos investigadores a partir de unas condiciones específicas de su entorno 
social e institucional. Por el tiempo, no puedo extenderme en un análisis de las características de toda la producción historiográfica, desde los años ochenta, y los noventa. Más bien, priorizaré el marco social e institucional en el que podemos enmarcar el libro de Eudald. ${ }^{1}$

Michel De Certeau se pregunta ¿Cuál es la obra de valor en historia? Y la respuesta es "la que es reconocida por los pares". La que puede situarse en un conjunto operativo. La que constituye un progreso en lo referente a la condición actual de los "objetos" y los métodos históricos, y que, ligada al medio en que se elabora, vuelve posible a su vez nuevas investigaciones. El libro de Eudald entonces, es el resultado del trabajo de un grupo académico que funciona como un laboratorio.

Es por ello, que podemos plantear que la investigación de Eudald se circunscribe en el trabajo de un grupo de académicos españoles americanistas interesados en la historia de las izquierdas en América latina. En la Universidad de Santiago de Compostela hay un núcleo de colegas encabezados por Eduardo Rey Tristán, director de la tesis doctoral de Eudald, y que sus investigaciones se han dedicado principalmente a la violencia política y los movimientos revolucionarios latinoamericanos contemporáneos, especialmente de Uruguay y Centroamérica. También es parte de ese grupo Pilar Cagiao, especialista del tema de migraciones.

A partir de este núcleo se ha venido conformando una red de especialistas que abordan desde distintas disciplinas y enfoques teóricos el tema de los conflictos o guerras civiles en América Latina. Por ejemplo, Alberto Martín Álvarez sociólogo y politólogo del Instituto Mora en Ciudad de México, ha venido desarrollando un intenso trabajo desde su tesis doctoral dedicada al estudio del FMLN y últimamente se ha interesado en la génesis de las organizaciones que conformaron dicha organización político militar. Por supuesto, este núcleo de académicos españoles se enmarca en una amplia red de estudiosos de la guerra civil española. En este sentido, el enfoque teórico metodológico empleado por Eudald, es decir, los aportes en este

1 Comentario pronunciado el 27 de noviembre de 2017 en el auditorio Elba y Celina de la Universidad Centroamericana "José Simeón Cañas", a propósito de la presentación de esta obra. 
campo realizados por los historiadores de la comunicación, los análisis que desde el mundo de las ciencias de la comunicación han abordado el proceso revolucionario en El Salvador y los teóricos de los movimientos sociales, lo realiza en constante diálogo con la experiencia española.

Es en esta comunidad académica en la que se inserta el trabajo y el libro de Eudald. Como les mencionaba, el libro tiene ya una trayectoria. En primer lugar, es el resultado de un intenso trabajo académico reconocido por los pares de esa comunidad científica que da como resultado una tesis doctoral en historia de alta calidad y que ahora ha sido transformada en un libro que aspira ser leído por un público más amplio.

Como ya lo advertí anteriormente, antes que libro este trabajo fue tesis, producida en un contexto social y académico pertinente. Creo que hay que agradecer tanto a Eudald como a UCA Editores que ese paso de convertirse de tesis a libro, conserve algunas características básicas, de la noción de historia-problema, la que está obligada a construir su objeto, explicitar sus hipótesis y reconocer sus procedimientos, esto abona para que libro sea abordado por un público amplio. Me refiero por ejemplo a que además del prólogo y la presentación se colocara una parte titulada "Una necesaria introducción metodológica", en la que el autor, plantea sus objetivos, las principales hipótesis, las fuentes y su tratamiento, su propuesta metodológica y algo sumamente importante como un estado de la cuestión, que relaciona su trabajo con otros, con investigadores contemporáneos, que plantean sus propias problemáticas, cuyos resultados de investigación han aportado al conocimiento de la historia de la guerra civil salvadoreña en particular, así como su relación con los procesos regionales, centroamericanos, latinoamericanos.

Cabe destacar en este ámbito la producción historiográfica que desde los inicios de la década de los noventa aparece. Por ejemplo, el trabajo de José Ignacio LópezVigil Las mil y una historias de Radio Venceremos que publicó UCA editores en 1991, o el trabajo de María Teresa Escalona La radio como instrumento de lucha política. Experiencia de Radio Farabundo Martí 1982-1992; y los trabajos de Luis Alvarenga, Tiempos de Audacia. Los mass media de una guerrilla y La gramática de la pólvora. Los debates en la prensa revolucionaria salvadoreña, 1971 - 1979 de reciente publicación por UCA editores. 
Ahora me quiero referir un poco a algunas características del libro enmarcadas en la noción de paratexto. En primer lugar, el título y subtitulo del libro. Creo que a veces subestimamos la importancia de sintetizar en el título de un libro la esencia del contenido del mismo. Eudald entrelaza hábilmente dos ideas fundamentales en el título. En primer lugar, hace alusión que si en algo coincidieron la insurgencia, los asesores estadounidenses y, en menor medida, el alto mando de la fuerzas armadas, fue la comprensión de que la guerra no se definiría en términos militares, y en segundo lugar, si como afirmara Clausewitz, la guerra es una mera continuación de la política, podemos asegurar - plantea Eudald- que la comunicación y la propaganda, como medios, son esferas particulares en las que se expresa la guerra y, en consecuencia, el conflicto político.

El subtítulo amarra hábilmente, el objeto de estudio. La comunicación insurgente, estudiándola como un proceso, en el marco del desarrollo de las estrategias y tácticas de la insurgencia y además, delimita el espacio temporal que abarca su trabajo, es decir 1970-1992. La imágenes, y la contraportada, complementan el mensaje que a primera vista veremos cuando tomamos el libro, es decir una temática concreta, en un medio espacial y temporal delimitado, así como las principales tesis.

Ahora quiero referirme a la operación que supone, que una vez una investigación ha desplegado toda una práctica, como ya lo mencioné se da en el marco de un lugar social e institucional específico, pasa a la escritura. En este caso, Eudald, después de realizar su trabajo de campo, de permanecer horas y horas en archivos nacionales (CIDAI, MUPI, Fundabril, etcétera) y en archivos extranjeros, dedicándole horas y horas de entrevistas de actores o sujetos históricos, estudiando las fuentes secundarias, acumulando con todo ello un corpus de fuentes, huellas, indicios, que le permiten de alguna manera transportarse al pasado que estudia, a una realidad que ya no es, y que debe plasmar en un papel la historia en forma de relato y desde el presente. Es decir, como lo ha planteado Michel De Certeau, realizar una explicación, la cual no es más que la manera que tiene el relato de organizarse en una intriga comprensible 
Si bien podríamos destacar muchos elementos del relato que construye Eudald, quiero destacar que, si bien los resultados de su investigación se exponen en orden cronológico, estableciendo una periodización, 1970, 1975, 1980, 1992, rompimientos y continuidades, coyunturas, dividiendo el libro en dos grandes partes 1970 a 1980 y de 1980 a 1992, etcétera, ha suavizado la rigidez de este orden, destacando elementos sincrónicos en los que podemos descubrir el mundo de las contradicciones entre las estrategias comunicativas desplegadas por las cinco organizaciones, en una relación dialéctica con sus estrategias político militares generales. En tal sentido, la configuración de las identidades de los militantes de cada organización, y que estaban íntimamente relacionadas con las estrategias comunicativas, principalmente a través de las publicaciones internas, nos transportan a aquellos escenarios para comprender cómo y porqué esos hombres y mujeres actuaron de una forma concreta en un momento concreto de la historia.

Para finalizar, dos cosas más. La primera, y que constituye un reto para el libro de Eudald, es que si bien el espacio temporal que propone va de 1970 a 1992, debemos estar claros que la cronología de una obra histórica no es si no un segmento limitado, tratado sobre un eje más amplio que se prolonga por ambos lados. Es decir, imaginemos que ponemos un hule sobre una línea de tiempo entre 1970 y 1992, podríamos estirarlo hasta 2017 sin que se rompa, por que los ecos del acontecimiento que trata llegan hasta nuestros días. En este caso, Eudald nos plantea la relación que la sociedad salvadoreña del presente mantiene no solo con los muertos del pasado, sino con muchos actores que están vivos, algunos de ellos entrevistados por Eudald y que podrán verse en la puesta en escena que se plantea. Por lo tanto, el libro de Eudald podríamos circunscribirlo también en la noción de historia del tiempo presente, la cual se plantea estudiar acontecimientos o procesos del que todavía vive una de tres generaciones que lo vivieron, es decir tiene un tejido vivo, por lo tanto estos actores pueden cuestionar el relato construido por Eudald, estableciéndose una relación interesante entre memoria e historia.

En esta misma sala, si les interesa, por supuesto, cada uno podrá aborda la lectura del libro desde ámbitos diferentes: algunos lo harán desde 
un punto de vista académico, los jóvenes estudiantes por un interés o por la curiosidad de conocer algo de la historia reciente de El Salvador y otros desde la memoria, porque vivieron en aquella época.

Para finalizar, quiero plantear que este libro, es capaz de provocar nuevas investigaciones, en ese sentido, a mí personalmente me provoca dos temas de interés.

1. Continuar con el estudio de la construcción de identidades.

2. A partir de los planteamientos de Roger Chartiere, estudiar la recepción de los contenidos de la propaganda, planteados por Eudald, a través de las estrategias de lectura y escuchas por las personas en el marco de un régimen autoritario como el salvadoreño.

Gracias por su atención. 